\title{
A Construção Social dos Papéis Sexuais Femininos
}

\author{
Eros DeSoura ${ }^{1}$ \\ John R. Baldwin \\ Illinois State University - EUA \\ Francisco Heitor da Rosa \\ Universidade Federal do Rio Grande do Sul
}

\begin{abstract}
Resumo
Esta revisão é uma tentativa de produzir uma representação holística, mas não exaustiva, dos papéis sexuais femininos no Brasil. Começamos traçando o papel histórico-político das mulheres do Brasil Colonial até o movimento feminista moderno, enfocando três questões correntes: planejamento familiar, creches e violência contra a mulher. A seguir, examinamos as normas culturais do machismo e do marianismo. Finalmente, discutimos os avanços que as mulheres fizeram no Brasil na última década (desde a Constituição de 1988), chamando a atenção para uma questão que tem sido grandemente ignorada: o assédio sexual. Palauras-chave: Discriminação; poder; papéis de gênero; assédio sexual.
\end{abstract}

Feminine Sex-Roles Social Construction

Abstract

This review is an attempt to provide a holistic, but by no means exhaustive, picture of gender roles in Brazil. We begin by tracing the historical-political role of women from colonial Brazil through the modern women's movement, highlighting three current issues: family planning, child care, and violence against women. Next, we examine the cultural norms of macbismo and marianismo. Finally, we discuss the strides women have made in Brazil in the last decade (since the Consitution of 1988), calling attention to one issue that has been largely ignored: sexual harassment.

Keywords: Discrimination; power; gender roles; sexual harassment.

"Quando meu marido me bateu e eu fui para a policia, me disseram para bater nele também. Não parece haver nenhuma protecão para as mulheres, especialmente em situaçoes violentas. Os homens não podem viver sem as mulheres e ainda assim eles nos tratam mal... eu quero que meus filhos tenham uma boa educação, que eles estudem para que não passem pela mesma situação que estou passando agora. Também quero encontrar trabalho." (Maria dos Anjos Ferreira, uma brasileira de classe baixa, em "Flight", 1995, p. 46)

Um novo entendimento sobre as mudanças sociais é necessário porque as contribuições femininas e os direitos femininos têm sido um tema central nos papéis sociais, econômicos e políticos mundialmente (World's Women, 1995). Nós propomos que é preciso que se aplique este foco também no Brasil, e que essa análise seja interdisciplinar. Pensamos assim por duas razões: 1) As teorias feministas e comunitárias criticam a psicologia tradicional por ser associal e apolítica; isto é, a mulher pobre tem sido silenciada e excluída na teoria e prática psicológica (DeSouza, 1998; Reid, 1993). 2) Embora cada cultura experimente uma realidade social única, nós estamos interligados. Se vivemos no Brasil, na Europa ou nos Estados Unidos, nós vivemos em uma

${ }^{1}$ Endereço para correspondência: Department of Psychology (4620), Illinois State University, Normal, Illinois, 61790, EUA. Fax (309) 4385789. E-mail: erdesou@ilstu.edu. comunidade cada vez mais pluralista devido à imigração, à economia globalizada e aos avanços tecnológicos (p. ex., televisão por satélite, Internet, crescente rede de transporte mundial) que nos ligam através de grandes distâncias (DeSouza, 1998). Especificamente, enquanto a opressão do sexismo parece manifestar-se "naturalmente" no Brasil, ela ainda assim é vista como opressão em outras culturas (Hecht \& Baldwin, 1998), como nos Estados Unidos.

Nosso objetivo é fornecer uma revisão do arquétipo feminino, o modelo de Maria, através de uma análise sócio-histórico-político-legal das condições que têm influenciado a vida da mulher brasileira. Acreditamos que esta análise é importante porque os fenômenos sociais são influenciados pelo contexto no qual estão inseridos. Hecht e Baldwin (1998) usam uma metáfora holográfica para sugerir que cada visão do sexismo contém uma imagem pequena, mesmo que distorcida, do todo - e 
que somente combinando pontos de vista de diferentes disciplinas e culturas seríamos capazes de obter uma visão completa e mais exata do sexismo.

Para facilitar nossa análise, este artigo é estruturado em três seções. A primeira seção fornece uma perspectiva histórico-política sobre o papel das mulheres no Brasil, incluindo três questões atuais que emergiram do movimento feminista: planejamento familiar, creches violência contra mulheres. A segunda seção examina as normas culturais do machismo e marianismo no Brasil, enquanto fornecedora de uma visão explicativa útil, através da qual podemos analisar a história. A terceira seção discute os avanços que as mulheres obtiveram recentemente, chamando a atenção para uma questão que tem sido amplamente negligenciada na literatura existente: o assédio sexual. Finalmente, oferecemos sugestões para futuras pesquisas.

Um Olhar Histórico Sobre o Papel das Mulheres no Brasil

O tema principal das relações de gênero durante a colonização é a miscigenação. A grande maioria dos colonizadores portugueses que se estabeleceram no Brasil foi de homens que tomaram a terra e as mulheres pela força. Eles mantiveram relações sexuais, primeiro com mulheres indígenas e, depois, com escravas africanas, produzindo uma elevada miscigenação (van den Berghe 1967). A escassez de mulheres portuguesas conferiu aos homens a licenciosidade sexual (Burns, 1993), aumentada pelo fato de que os colonizadores portugueses não estavam sujeitos nem ao fervor católico dos espanhóis nem à inibição pudica dos protestantes ingleses (Levine, 1989). Portanto, os homens portugueses mantiverem relações sexuais com mulheres africanas, que eram vistas primeiramente em dois papéis: como trabalhadoras e como objetos sexuais.

Quando as mulheres brancas chegaram durante a era Colonial, elas mantiveram o arquétipo do modelo de Maria - elas eram assexuadas; suas vidas restritas aos limites da casa ou da Igreja. As mulheres eram estereotipadas como fracas, submissas, passivas e sem poder na área pública. Em vez de receber uma educação formal, elas eram treinadas para o casamento (da Costa 1985) - para administrar a casa, criar os filhos, e "tolera as relações extra-matrimoniais do marido com as escravas" (McCann \& Conniff, 1989, p. xii). Da Costa (1985) sugere que tais ligações existiam em harmonia dentro dos preceitos religiosos da época, os quais favoreceram a miscigenação.

Durante a era Imperial, as mulheres lutaram para ampliar seus papéis na sociedade. A rígida disciplina patriarcal que tinha excluído as mulheres de classes média e alta enfraqueceu-se: tornou-se de bom-tom o trânsito de mulheres nas ruas e sua posição melhorou no mercado de trabalho (da Costa, 1985). Pôde-se ver avanços na luta por direitos no campo do trabalho, da educação e da política, áreas tipicamente dominadas pelos homens.

$\mathrm{Na}$ virada do século, as mulheres ganharam emprego em ferrovias, nas atividades telegráficas, nos correios, na enfermagem e secretariado, e na área de produção (Burns, 1993, Hahner, 1990). De 1872 a 1900, a percentagem de professoras nas escolas primárias dobrou, de um terço para dois terços, pois o magistério era uma extensão natural do papel das mulheres como cuidadoras, mantendo o arquétipo do modelo de Maria. A entrada das mulheres nesta profissão resultou na redução do salário dos educadores (Hahner, 1990).

Assembléias de mulheres levantavam e debatiam questões pertinentes às mulheres como força de trabalho, tais como licença-maternidade, horas de trabalho, salários e condições de trabalho (Conniff \& McCann, 1989); no entanto as reformas propostas excluíam os interesses das mulheres da classe operária. Porém, a Lei Comercial de 1850 proibiu que as mulheres participassem do comércio sem a permissão de seus maridos (Graham, 1990). Topik (1989) nota que as mulheres ocupavam poucas posições econômicas proeminentes no Brasil durante a República Velha; as carreiras femininas não deveriam "estender-se além dos problemas do coração" e "seu mundo ...(deveria ser) limitado ao de filha, esposa e mulher" (Hahner, 1990, p. 51). O folclorista brasileiro Alexandre José de Melo Moraes Filho ecoava o sentimento do modelo de Maria: "Ser mãe, mulher e virgem — Este é o objetivo da mulher, nada mais!" (Hahner, 1990, p. 53).

As mulheres tornaram-se pioneiras nas áreas da política, na força de trabalho, na educação e na imprensa no início do século XX (Hahner, 1990), embora as condições de trabalho fossem terríveis e discriminatórias. Por exemplo, mulheres não tinham direito a férias remuneradas ou segurança no trabalho e sua jornada chegava a 16 horas de trabalho diárias, embora, para muitos homens, a carga horária diária já havia sido reduzida para oito horas (Burns, 1993). Os supervisores freqüentemente usavam a força contra mulheres e crianças (Hall \& Garcia, 1989).

Alguns periódicos femininos, com leitores limitados a classe média e alta, mencionavam direitos para as mulheres (Conniff \& McCann, 1989; da Costa, 1985), mas estes periódicos enfatizavam, ainda, "a vocação natural" das mulheres - de serem mães e esposas. Em 1910, o Partido Republicano Feminino foi formado como um local para as mulheres expressarem suas 
opiniões, embora elas ainda não tivessem ganho o direito ao voto. Através deste partido, as mulheres lutavam por sua emancipação, incluindo a representação no setor de prestação de serviços e no sufrágio feminino (Hahner, 1990). Logo após as mulheres terem ganho o direito de voto, no ano 1932, o Presidente Getúlio Vargas fechou o Congresso, tornou os partidos políticos ilegais e suspendeu os direitos de voto em nível nacional, "terminando com a política eleitoral e com a participação das mulheres até 1945" (Hahner, 1990, p. 174). Apesar do retorno da democracia ao Brasil depois disto, e mesmo após o golpe militar de 1964, o movimento feminista fez pouco progresso, até o início dos anos 70.

\section{O Movimento Feminino desde 1970}

Nos anos 70, um "novo movimento feminista" emergiu no Brasil (Hahner, 1990). O Zeitgeist (espírito dos tempos) era propício para um grande avanço: foi na metade dos anos 70 que "as mulheres de classe média, de nível universitário, e mulheres pobres, sem educação, organizaram movimentos para que suas reivindicações políticas feministas fossem incluídas no sistema político brasileiro" (Alvarez, 1989, p. 205). No mínimo três influências parecem agir para criar esta conjuntura histórica.

Primeiro, no sentido político, a ditadura militar estava mostrando sinais de fraqueza. Começando em 1975, durante a presidência de Ernesto Geisel, começou a abertura, permitindo mais liberdade ao movimento político, com as feministas dando seu apoio à oposição (Alvarez, 1989). As forças políticas estrangeiras também tiveram um impacto positivo sobre o movimento das mulheres, enquanto que as Nações Unidas, em um esforço para acabar com a desigualdade entre os sexos, apoiou o Dia Internacional da Mulher. Geisel permitiu que as mulheres realizassem encontros, demonstrações e conferências para comemorar este dia. Alvarez (1989) assinala esta ocasião, em 1975, como sendo o nascimento do movimento moderno das mulheres no Brasil.

Uma segunda influência foi o lugar da mulher na economia. Alvarez (1989) cita estatísticas que mostram que na década de 70, a participação feminina na população economicamente ativa (PEA) brasileira aumentou de $18,5 \%$ para $26,9 \%$. A participação feminina na PEA em posições administrativas quase dobrou entre 1960 e 1980 - de $8,2 \%$ para $15,4 \%$. O número de mulheres em profissões de alto prestígio (p. ex., engenheiras, economistas, médicas, professoras universitárias e advogadas) cresceu aproximadamente 400\% nessa década, de 19.000 em 1970 para 95.800 em 1980. Em 1980, já havia aproximadamente o mesmo número de Psicologia: Reflexão e Crítica, 2000, 13(3), pp.485-496 homens e mulheres brasileiros nas universidades (689.000 homens e 663.000 mulheres).

Atualmente, a maioria das mulheres trabalha para ajudar a sustentar a família, com as mulheres formando $51 \%$ da força de trabalho e $45 \%$ de todos os eleitores registrados (Rabay, 1996). Porém, ainda havia (e continua havendo) uma grande discrepância econômica em comparação aos homens, sendo esta discrepância maior nas profissões bem remuneradas e menor (quase nula) entre mulheres e homens pobres e analfabetos (Neuhouser, 1989).

Terceiro, houve uma mudança na direção da religião. A Igreja católica, tendo estado ao lado das elites por séculos, tomou uma nova posição no Brasil por volta dos anos 70, voltando-se às necessidades das massas (Alvarez, 1989). A Teologia da Libertação deu apoio social aos oprimidos. Ou seja, os padres sensibilizaram os trabalhadores e os pobres com relação a sua situação difícil e, em alguns casos, forneceram estratégias para que eles se dirigissem à elite e ao governo (Boff, 1992). Formaram grupos comunitários, chamados comunidades eclesiásticas de base, ou CEBs, que freqüentemente dedicavam-se à ação social ou política. Estes grupos freqüentemente eram liderados por mulheres (Neuhouser, 1989). As religiões afro-brasileiras também forneceram força libertadora para as mulheres, especialmente entre as pobres, oferecendo-lhes modelos de papéis positivos (p. ex., mãe-de-santo), compensando a falta de poder que elas experimentam na sociedade (Larch, 1982). Neuhouser (1989) sugeriu que essas religiões concedem às mulheres uma liberação através de rituais de possessão espiritual: "uma mulher que é possuída está 'livre' para desobedecer seu cônjuge quando os desejos dele conflituam com aqueles dos espíritos" (p. 701). As duas religiões reformulam o arquétipo de Maria para dar um lugar libertador à mulher em papéis de liderança e aconselhamento.

Os fatores acima ajudaram as mulheres a ter um papel mais visível na estrutura das relações sociais no Brasil. Por exemplo, mães começaram campanhas políticas locais em suas comunidades. Essas campanhas cresceram e abrangeram o país inteiro, como o Movimento Feminino pela Anistia, o Movimento Custo de Vida e o Movimento de Luta por Creches (Alvarez, 1989). De acordo com Alvarez (1990), essas campanhas focalizaram nos papéis de gênero e "feminizaram" a política durante a abertura. Várias questões foram abordadas. Contudo, o planejamento familiar, o cuidado de filhos fora de casa (em creches) e a violência contra as mulheres são as três questões que parecem formar o foco da tentativa das mulheres para redefinir seu papel em relação à família. 
Ou seja, cada uma destas questões é uma reação ao posicionamento histórico da mulher na família brasileira. "A família, óbvia e abstratamente ... tornou-se o alicerce do novo regime autoritário no Brasil, funcionando freqüentemente como um baluarte do conservadorismo na América Latina" (Alvarez, 1989, p. 214).

Planejamento familiar. A primeira questão a ganhar grande atenção política na história recente foi o planejamento familiar. Historicamente, o Brasil tem sido um país que se opõe a qualquer tipo de controle de natalidade. Isso começou a mudar em 1978, quando o presidente Geisel sugeriu que o governo se responsabilizasse em fornecer os meios para o controle de natalidade. Algumas medidas de planejamento familiar foram instituídas, com a abertura de várias clínicas de cuidados materno-infantil, em Brasília, para distribuir pílulas anticoncepcionais para mulheres indigentes (Alvarez, 1989). Subseqüentemente, a taxa de natalidade caiu dramaticamente em Brasília. A taxa total de fertilidade reduziu-se de 5,76 em 1970 (IBGE, 1984) para 3,38 em 1989 (UNICEF, 1990). Em 1986, 71\% de todas as mulheres brasileiras em idade fértil usavam algum tipo de contraceptivo; destas, 44,4\% foram esterilizadas e 41\% usava pílulas para controle de natalidade (Berquo, 1989).

Aconteceu uma batalha entre os grupos pró-natalista e pró-controlista sobre a distribuição de pílulas anticoncepcionais, uma batalha não simplesmente relacionada a gênero ou a escolha, mas a economia e a raça. Por exemplo, esterilização forçada ou a distribuição indiscriminada de pílulas anticoncepcionais foi mais freqüentemente direcionada às populações pobres e às não-brancas (Alvarez, 1989; Berquo, 1989). As feministas opuseram-se à separação da saúde sexual de outros aspectos da saúde feminina. As feministas contribuíram com o aumento da consciência para o debate sobre o planejamento familiar, através de sucessivos acordos do IV Congresso Feminista Nacional (São Paulo, Julho de 1984) e o I Encontro Nacional sobre a Saúde da Mulher (Itapecirica da Serra, Novembro de 1984), sendo que ao último compareceram mais de 400 mulheres de 19 estados brasileiros. Ou seja, elas queriam que o planejamento familiar fosse uma questão de debate público, não uma decisão governamental fechada. O mais interessante nesta discussão é que uma das maiores questões do movimento da mulher refere-se à maternidade, um tema central do modelo de Maria.

Cuidado dos filhos. Talvez devido a influência do modelo de Maria, uma área que distingue mais o movimento feminista no Brasil dos de outros países é a questão do cuidado dos filhos. Especificamente, tem existido alguma força política para as empresas manterem o modo de cuidar os filhos das trabalhadoras - isto é, a creche. Alvarez (1989) descreve este esforço em detalhe. Ela nota que a manutenção de creches por empresas com mais de 30 funcionárias tem sido mantida pela lei desde 1943, mas não tem sido fortemente reforçada. Começando no início dos anos 70, grupos comunitários lutaram por fundos governamentais locais para creches. Estes grupos, no I Congresso Feminino de São Paulo, em 1979, começaram um movimento para obter creches gratuitas para todas as mulheres trabalhadoras. $\mathrm{O}$ movimento por creches explodiu, com dúzias de manifestos femininos dirigidos ao governo estadual, com sucesso. Reinaldo de Barros, o novo prefeito de São Paulo, em 1979, deu às creches um lugar central em sua plataforma neo-populista, prometendo construir um total de 830 creches. Além disto, estas creches deveriam ser completamente sustentadas e administradas diretamente pelo governo, para garantir controle e qualidade do serviço. Mas, no fim, ele só construiu 141 creches e "aproveitou-se politicamente apontando previamente todos os diretores das creches a serem construídas" (Alvarez, 1989, p. 227).

Sob uma nova administração da prefeitura, e passando pela crise de débito nacional de 1982 a 1983, a situação passou de mal a pior. As creches recebiam somente fundos municipais parciais e eram administradas por agências privadas, o que os grupos feministas sentiram "excluía a participação da comunidade da administração das creches - uma exigência fundamental do movimento desde sua fundação" (Alvarez, 1989, p. 228). Vários partidos políticos tentaram encampar o movimento por creches. Finalmente, "tudo o que restou do movimento de base anteriormente maciço e unido foi dispersado, em grupos de creches comunitárias” (p. 229). Parece que, quando as mulheres foram necessárias no mercado de trabalho, as creches foram criadas para seus filhos (Santana, 1996), mas quando apareceu o quanto iriam a custar ao sistema capitalista, foram abandonadas.

Tendo em vista o esfacelamento do movimento por creches, Alvarez (1989, 1990) conclui que o encampamento político de qualquer questão deteriora a mesma, por outro lado, movimentos de base comunitária e bipartidários freqüentemente têm os melhores efeitos na direção de mudanças positivas. Alvarez (1989) também nota que a direção de qualquer questão não está determinada meramente por classe, mas por uma conjuntura de variáveis. Estas variáveis incluem ligações do regime a interesses nacionais e internacionais, por exemplo, bancos, investimentos multinacionais, partidos políticos, e, é claro, as ideologias de gênero, classe, e raça. As mulheres têm um papel importante, diz Alvarez, em intervir nestas variáveis para alterar o seu próprio papel. 
Violência contra a mulher. O Brasil ainda permanece uma sociedade profundamente patriarcal, onde crimes cometidos contra mulheres são comuns. Entre Janeiro de 1991 e Agosto de 1992 foram registrados 205.219 casos de violência contra a mulher no Brasil (Neto, 1996). Contudo, alguns acreditam que a maioria dos crimes contra a mulher não são sequer registrados devido à falta de punição aos agressores (Americas Watch, 1991). Especificamente, a ineficiência e inadequação geral do sistema judiciário brasileiro, formada por uma mistura de preconceito e incompetência óbvia por parte da polícia faz com que as mulheres não procurem justiça.

Esta impunidade baseia-se em três fatores, no mínimo: 1) os agressores têm sido absolvidos com base na "defesa da honra"; isto é, um homem pode ser levado a matar a companheira infiel por ela ter insultado sua honra (Brooke, 1982). Embora a defesa da honra não seja mais empregada em nível federal, Americas Watch (1991) nota que, em nível estadual, a defesa da honra ganhou aproximadamente $80 \%$ das causas. 2) Há problemas na linguagem da lei em si. Os códigos são restritivos em termos de suas definições de estupro, agressão e assim por diante (Americas Watch, 1991; Thomas \& Beasley, 1993). Por exemplo, o estupro consiste somente na penetração vaginal com ameaça de violência à mulher; $\mathrm{e}$, até o código mais recente, a mulher deveria ser virgem, para que o caso fosse levado adiante. Além disto, se o agressor fosse o marido, ele poderia ser visto como se estivesse simplesmente forçando "relações conjugais", o que constituiria um "problema privado" (Thomas \& Beasley, 1993). 3) A polícia não lida adequadamente com os casos que são relatados (Americas Watch, 1991).

Vários protestos fizeram que o governo federal implantasse Delegacias de Defesa da Mulher (DDMs), completamente atendida por mulheres e para mulheres. Estas delegacias tinham seus próprios problemas: horário de funcionamento e localizações limitados, escassez de médicos legistas para determinar abuso sexual, falta de treinamento das policiais e o continuado maltrato que as vítimas sofriam anteriormente. Todos estes fatores contribuíam para impedir que as mulheres relatassem crimes violentos às novas delegacias (Americas Watch, 1991; Nelson, 1996; Thomas \& Beasley, 1993). De um total de 54.472 incidentes violentos registrados em São Paulo no primeiro semestre de 1994, somente 12.219 foram investigados, e o número de casos julgados foi menor ainda (Americas Watch, 1991; Nelson, 1996). Nelson sugere que há um grande aumento da consciência da violência contra as mulheres, mas ainda a "baixa taxa de julgamentos" e a indiferença com relação a isto em muitas localidades, faz com que a maioria dos casos sejam "arquivados e esquecidos" (pp. 139-140).

Não deveríamos rejeitar totalmente o sucesso das Delegacias, do SOS Mulher e de outros esforços para reduzir a violência. Estatísticas da Paraíba (comunicação pessoal com o Centro da Mulher, em 08/03/1996) mostram uma tendência de diminuição em alguns crimes violentos contra a mulher (ex.: lesões corporais e ameaças de morte) de 1994 a 1996. Nelson (1996) sugere que existem fatores para se estimar o sucesso das delegacias além da taxa de julgamentos, tais como serviços prestados a milhares de mulheres a cada ano. Outro raio de esperança é o surgimento de abrigos para mulheres agredidas. Também, a nova Constituição, aprovada em 1988, "prevê a legalização de legislação específica para prevenir e punir abusos, não somente contra a mulher, mas também contra crianças e idosos" (Verucci, 1991, p. 563). Deseja-se que sejam feitos progressos em termos de definição e no reforço da punição com o próximo Código Penal.

\section{A Construção Social dos Significantes Sexuais}

A discussão prévia sobre violência contra a mulher revela que as afirmações feitas por advogados e juizes com relação à defesa da honra não tinham referência com a infidelidade do marido, ou com o direito da mulher de matar seu marido para defender a honra dela. Isto pode ser causado por uma visão patriarcal refletida em uma afirmação de Lopes de Oliveira, um especialista em Vara de Familia no Brasil:

"Quando um homem viola a lealdade conjugal, ele o faz por causa de um desejo fútil. Isto não destrói o amor da mulher, ou o fundamento da sociedade conjugal. $\mathrm{O}$ adultério da mulher, ao contrário, afeta a ordem interna da família, comprometendo a estabilidade da vida conjugal. $\mathrm{O}$ adultério da mulher é mais sério, não somente pelo escândalo que causa, mas também porque fere um maior número de valores e a lei mais profundamente. Há perigo de a mulher introduzir crianças estranhas dentro do lar." (Americas Watch, 1991, p. 22)

A citação acima confirma duas noções sobre o adultério feminino: 1) isto é socialmente inaceitável, porque vai contra o assim chamado papel natural das mulheres como mães e, através do seu serviço à família, como progenitoras da nação; por outro lado, os homens estão livres para preencher seus desejos pessoais quase sem alguma reprimenda social (Neuhouser, 1989). Desde a era colonial, havia uma construção diferente do adultério para homens e para mulheres: "o comum estava no encarar-se como absolutamente natural a punição da adúltera pela morte. $\mathrm{O}$ homem, ao contrário, não se sujeitava a penas maiores por experiências extra- 
matrimoniais com mulheres solteiras ou com escravas e prostitutas" (Araújo, 1993, p. 231). Portanto, se uma mulher comete um crime contra a família ou a cultura (ex.: adultério), acredita-se que ela mereça seu castigo, seja ele violência sexual ou assassinato, e que os homens que cometem adultério estão somente expressando sua masculinidade natural. 2) Embora muito relacionado ao primeiro, a sexualidade feminina é construída para ser subordinada às necessidades do marido. O homem é visto tipicamente como o provedor, aquele que sustenta a família, o representante legal e assim por diante (Americas Watch, 1991; Barker \& Lowenstein, 1997). As instituições sociais muitas vezes têm agido de maneira a negar às mulheres o direito de exercer seu poder publicamente.

\section{Machismo e o Modelo de Maria (Marianismo)}

Os papéis de gênero condizem com interpretações tradicionais do Brasil como tendo uma cultura machista. Muitos tentaram resumir o machismo como ele aparece no mundo latino. Especialmente em termos do mundo hispânico no hemisfério ocidental, o machismo tem sido descrito como uma norma cultural que engloba todas as características que são verdadeiramente "masculinas". Muitos descreveram o machismo em termos de indiferença a família, distanciamento dos filhos, resistência à adversidades, assédio sexual, capacidade de beber muito, agressividade contra outros homens, dominação em relação às mulheres. De la Cancela (1986) afirma que "O machismo é um conjunto de condutas - construídas, aprendidas, e reforçadas culturalmente — que encerra o conteúdo dos papéis de gênero masculino na sociedade latina" (p. 291). Outros concordam que cada cultura constrói discursos específicos de masculinidade ideologias masculinas, por fala, por mídia, por música e literatura popular, e por lei (e.g., Foucault, 1978).

No contexto brasileiro, diz-se que o machismo glorifica a hipermasculinidade. Na verdade, o machismo pode ser maior no Brasil do que em culturas com maior população indígena (Neuhouser, 1989); ou seja, as relações sexuais entre os homens e mulheres brasileiros começaram dentro do contexto de uma sociedade colonial escravocrata, onde os homens brancos tinham poder e autoridade absolutos sobre as mulheres de cor (Burns, 1993; Levine, 1989). No Brasil, opina Neuhouser (1989), o machismo é mais que os comportamentos dos homens - é a ideologia que promulga que é bom e até natural que eles controlem o mercado, o governo, e a atividade pública, e que as mulheres sejam subordinadas a eles.

A contrapartida do machismo, o modelo de Maria idolatra a mulher mártir que se auto-sacrifica, que é submissa aos homens, e que é uma boa mãe e esposa (Neuhouser, 1989). Pescatello (1973) descreve estes traços na cultura brasileira como um "ideal passivo feminino" (p. 56). A versão brasileira do marianismo é parecida com a descrição da castidade e da dedicação materna da Virgem Maria (Stevens, 1973) encontrada em outros países latinos, onde o marianismo é "exemplificado por extrema feminilidade, passividade e auto-abnegação" (González, 1982, p. 331); o marianismo é também chamado de "síndrome da mulher auto-sacrificada" (Lara-Cantú \& Navarro-Arias, 1987, p. 332-333). Del Priore (1993) conecta esta construção aos tempos coloniais, quando a sexualidade da mulher era circunscrita pela escravidão e pelo "projeto normatizador da Metrópole" (p. 26). Estas forças sociais, ela sugere, contribuíram para: "o longo processo de domesticação da mulher no sentido de torná-la responsável pela casa, a família, o casamento e a procriação, na figura da "santamãezinha" (p. 26). A imagem desta "santinha" está ligada à pureza da Virgem Maria- "provedora, piedosa, dedicada e assexuada" (p. 18).

Algumas pessoas desafiaram esta visão negativa do machismo e do marianismo, sugerindo que ela propaga estereótipos negativos da sexualidade latina (González, 1982; Sorenson \& Siegel, 1992). Eles redefiniram o machismo para vinculá-lo a aspectos mais nobres do "cavalheirismo", tais como educação nobre e a autoestima. Mirandé (1985) filtra os aspectos mais negativos do machismo, tais como a covardia, abuso, falta de vergonha e embriaguez, e, ao invés disto, vê o machismo como "o orgulho, a dignidade e a tenacidade do povo mexicano, já que ele resistiu ao ataque violento do controle econômico, político e cultural” (p. 179). Baca Zinn (1982) fala que a noção tradicional do machismo mexicano é um mito estereotipado, apoiando esta contenda com estatísticas mostrando que decisões nos lares mexicanos são mais igualitárias do que nos lares dos americanos brancos. No Brasil, homens jovens e pobres, mesmo considerando um aspeto chave de ser homem "pôr-se ativo sexualmente", também associaram "sustentar-se a si mesmo e a sua família" como uma parte importante de ser homem (Barker \& Loewenstein, 1997, p. 182).

Miele (1992) conclui que os estereótipos tradicionais de fragilidade, morbidez e fraqueza da mulher brasileira são imagens mais recentes. Desde os tempos mais remotos, as mulheres têm tido posições de liderança. Miele (1994) investigou como as mulheres se tornaram líderes de sindicatos de trabalhadores na Paraíba. Ela questiona se isto é um preenchimento do hino adotado pelo estado, que proclama: "Paraíba feminina, mulher forte sim senhor". Por esta noção, as mulheres da Paraíba são definidas como 
mulheres fortes e masculinas. Contudo, através de análises comparativas de líderes em outras regiões, ela conclui que a força das mulheres da Paraíba não pode ser considerada causa do índice proporcionalmente alto de líderes sindicais, optando pela proposição de que os papéis destas mulheres como mães, cuidadoras e professoras (em um campo onde poucos homens lêem e escrevem bem), ajudou-as a obter poder. As mulheres poderiam estar ocupando as posições de liderança com base em velhas imagens estereotipadas - ou arquetípicas - das mulheres; mas é nestas imagens - mãe, professora - que as mulheres são providas de poder. Os homens cedem a liderança dos aspectos de criação e educação às mulheres. Com o passar do tempo, contudo, o "aprendiz [vem] a tornar-se um mestre" (p.12): as mulheres acabam com mais poder do que os homens haviam proposto.

A manifestação exata do machismo e do marianismo no Brasil ainda precisa de mais investigação. Casas, Wagenheim e Mendoza-Romero (1995) sugerem que a pesquisa revela uma similaridade do machismo na maior parte do mundo; por exemplo, até mesmo seus elementos menos picantes, tais como duplo padrão sexual, pode claramente ser visto nas universidades americanas, onde mulheres com múltiplos parceiros masculinos são chamadas de "sluts" (prostitutas), enquanto homens com múltiplas parceiras são chamados de "studs" (garanhões). Isto é evidenciado por nosso conhecimento pessoal de universidades americanas, nas quais dizem que os homens que retornam de madrugada dos dormitórios femininos estão caminhando na "walk of fame" (calçada da fama), enquanto que as mulheres que retornam dos dormitórios masculinos estão caminhando na "walk of shame" (calçada da vergonha).

Arrazola e Rocha (1996), em vez de falar em termos de machismo, falam sobre o espaço público e privado no Brasil. O espaço público é "tipicamente masculino". É “o espaço da produção social”, incluindo educação, trabalho, política e literatura. O lar é tradicionalmente o espaço feminino, "o espaço da produção e da sobrevivência doméstico-familiar" (p. 49). A cultura brasileira, como outras culturas ao redor do mundo, valida a esfera pública, social e econômica (masculina) e desvaloriza a esfera privada (feminina). Neuhouser (1989) entende que o espaço doméstico não é desprovido de poder. Pelo contrário, a casa "fornece um contexto dentro do qual outros recursos estão disponíveis e podem ser usados" (p. 691). Isto pode incluir o controle sobre aquisição, preparação e consumo de comida, o controle sobre problemas domésticos diários e a educação e criação dos filhos. Isto ressoa o que dizem alguns escritores sobre um aspecto do marianismo que dá poder às Psicologia: Reflexão e Crítica, 2000, 13(3), pp.485-496 mulheres (Pescatello, 1973; Stevens, 1973). Além disto, os papéis de gênero estão mudando rapidamente devido a industrialização e urbanização do Brasil. Hoje, os casais jovens de classe média tendem a ser mais igualitários, abandonando a idéia de que as mulheres deveriam se subjugar aos homens (Miller, 1979).

\section{A Complicação nos Papéis de Gênero}

Possivelmente ligadas à industrialização e à educação formal, também existem diferenças nas atitudes com relação aos papéis de gênero entre brasileiros de diferentes setores, tais como urbano/rural, classe média/classe baixa e até mesmo entre pessoas de classe média que possuem curso superior e aqueles que não (Muraro, 1992). Há uma "grande transformação" acontecendo entre as pessoas de classe média, enquanto as camponesas suportam o peso da opressão (p. 157). Ou seja, estas mulheres têm que trabalhar mais duro do que mulheres urbanas e sofrem grandes restrições sobre sua sexualidade. A população rural tende a ter visões mais tradicionais dos papéis de gênero, do que as visões mais liberais das pessoas de classe média e, especialmente, dos universitários (Muraro, 1983). Muitas mulheres entrevistadas em um estudo de Muraro, sentiam que os homens "têm todas as vantagens, as melhores posições e os privilégios sociais, profissionais, todos" (p. 112). Algumas percebem que os homens têm mais variedade sexual e mais liberdade para ser "dono de si mesmo", o que se liga à percepção de que os homens têm uma vida melhor e mais agradável.

Dependendo da classe e da região do país, Muraro (1983) acha que alguns homens são mais igualitários do que as mulheres. Mas, acima de tudo, no Brasil, como em qualquer outro lugar, as possibilidades sexuais disponíveis para as mulheres são menores se comparadas àquelas que são oferecidas aos homens (Parker, 1988). Isto é evidenciado por análises de termos lingüísticos usados no dia-a-dia: uma distinção especial emergiu entre a atividade masculina e a passividade feminina, na qual a sexualidade feminina está sujeita ao desejo masculino (Parker, 1993). De acordo com Parker, tal distinção está refletida na linguagem diária que os brasileiros usam para descrever as relações sexuais, na qual o papel do macho é o de "comer" e o papel da fêmea é o de "dar". No universo sexual brasileiro, "comer" é sinônimo de vencer e possuir. Tal vocabulário de significantes sexuais é indicativo de que as mulheres são socializadas para serem passivas, parceiras sexuais receptivas, enquanto que os homens são socializados para perseguir, penetrar e dominar. Mesmo que haja alguma universalidade cultural do machismo, a cultura brasileira provavelmente construirá as especifidades diferentemente. Por exemplo, 
no Brasil, como no México, o machão continua a exercitar o poder de sua virilidade com qualquer indivíduo feminino, bicha ou homossexual masculino afeminado (DeSouza, Madrigal \& Millan, 1999; Mendes-Leite, 1993). Em outras palavras, desde que o macho mantenha sua atividade (ex.: seja a pessoa ativa ou penetrador, não o penetrado), ele não é visto como um homossexual no Brasil, enquanto que nos Estados Unidos os homens somente são "machos" se suas "conquistas" são mulheres (Parker, 1993).

Diferentes grupos étnicos ou raciais podem também ver os papéis de gênero diferentemente. Muraro (1992) entende que a posição das mulheres negras na favelas é bastante diferente culturalmente do que a das mulheres brancas; as primeiras são menos dependentes dos homen para criar os filhos e são mais sexualmente permissivas do que as últimas. Ao mesmo tempo, Freitas (1996) argumenta que a posição econômica das mulheres negras não mudou muito desde os dias de escravidão; ou seja as mulheres negras têm menos educação formal e tendem a ter empregos que pagam consideravelmente menos, tais como empregos na indústria ou como empregadas domésticas. Por um lado, devemos ser cuidadosos para não generalizar demais os papéis de gênero dos negros. Hall (1992) sugere que falar sobre grupos étnicos em termos de generalidades esconde a diferença entre segmentos de um grupo. Por outro lado, Muraro (1992) argumenta que o corpo feminino liga todas as mulheres: "Na última instância, que os nossos corpos são a máquina que faz o sistema funcionar, e nossa sexualidade, o seu combustível. E a família, a sua fábrica" (p. 158).

Sexualidade e Papéis de Gênero: Estudos Empíricos

Ultimamente vários estudos empíricos têm examinado as normas culturais dos duplos padrões sexuais. Po exemplo, DeSouza e Hutz (1995) examinaram a relação entre reação emocional a estímulos sexuais e papéis de gênero entre 184 universitários brasileiros. Eles descobriram que as exigências do papel de gênero (ex. ser passivo, condescendente) eram particularmente forte para as mulheres brasileiras, com mulheres tipificadamente femininas estando menos confortáveis com sua sexualidade do que mulheres andróginas. DeSouza e Hutz sugeriram que, para algumas mulheres (ex.: tipificadas), a atividade sexual existia primeiramente para a satisfação do homem.

Em um outro estudo conduzido por DeSouza, Pierce, Zanelli e Hutz (1992) com universitários americanos brasileiros, quatro situações foram manipuladas: um personagem feminino fictício havia consumido álcool (ou não) e havia aceitado o convite de um homem para ir até o seu apartamento (ou não). DeSouza e colaboradores descobriram que os brasileiros, independente do sexo dos participantes, mostraram maiores atribuições de intenção sexual da parte da personagem feminina em todas as quatros situações. Os autores sugeriram que os brasileiros eram mais estereotipados e erotizados que os americanos.

Em outro estudo comparando universitários americanos e brasileiros (DeSouza \& Hutz, 1996), ficou evidente, através de dados qualitativos e quantitativos, que os respondentes americanos e brasileiros tinham conceptualizações divergentes a respeito de como um encontro heterossexual hipotético poderia se desenvolver, dados dois contextos preliminares de resistência consistente ou inconsistente por parte do personagem feminino com relação aos avanços sexuais de um homem. Os respondentes brasileiros inferiam que relações sexuais consensuais eram um resultado natural no contexto da resistência inconsistente, ao contrário do que no contexto da resistência consistente, ao passo que o contrário foi encontrado entre os respondentes americanos. Somente no Brasil alguns respondentes inferem que algumas mulheres fazem-se de difíceis para evitar que sejam chamadas de "fáceis". Ainda, os brasileiros inferiram mais interesse sexual da parte da mulher do que os americanos. Portanto, de acordo com o padrão cultural brasileiro, quando um homem faz avanços sexuais e uma mulher não mostra uma resistência forte e consistente, pensa-se que ela está concordando com a relação sexual.

Estas pesquisas sugerem que o Brasil é mais sexualizado do que os Estados Unidos. Esta sexualização pode influenciar relações sociais e a comunicação da sexualidade no trabalho. Portanto é provável que o assédio sexual seja percebido diferentemente no Brasil do que nos Estados Unidos

Novos Rumos para as Questões da Mulher: Assédio Sexual no Brasil

Até bem pouco tempo, a sociedade brasileira ignorou uma questão que veio dominar a política de gênero americano: assédio sexual. Se o objetivo da nova constituição é, na verdade, criar um "corpus de legislação que seja igualitário e efetivo” (Verucci, 1991, p. 560), para ajudar as mulheres a "alcançarem a emancipação econômica" (p. 567), para livrar o país do abuso dos direitos humanos, de "tratamento desumano e degradante” (Patai, 1991, p. 556), então deveríamos querer erradicar um tratamento com relação às mulheres que possa inibí-las ou tratá-las injustamente (ex.: assédio sexual). 
Neste momento, um debate controverso no Brasil diz respeito a considerar ou não o assédio sexual como crime.

Nos Estados Unidos, a maioria das políticas e definições legais de assédio sexual é formulada de acordo com as diretrizes da Equal Employment Opportunity Commission (EEOC - Comissão para uma Igual Oportunidade de Empregos), a qual define assédio sexual como um comportamento sexual indesejável; existem duas formas básicas de tal comportamento: (1) quid pro quo e (2) ambiente hostil (EEOC, 1980). A primeira forma refere-se a ofertas de compensações ou ameaças para se obter envolvimento romântico ou sexual, enquanto a última refere-se a atenção sexual indesejada, que cria um ambiente intimidador, ofensivo e hostil (Fitzgerald \& Hesson-McInnis, 1989).

Pesquisas mostram que o comportamento que pode ser considerado como o assédio sexual (no mínimo, como formulado na literatura americana) existe no Brasil. Gelfand, Fitzgerald e Drasgow (1995) descobriram que universitários brasileiros e americanos não relataram diferença na real incidência de comportamentos específicos que constituem assédio sexual. Além disto, Pryor e colaboradores (1997) descobriram que 14\% dos estudantes brasileiros estudados relataram que tinham "provavelmente" ou "definitivamente" sido assediados sexualmente (comparados com $0 \%$ de alemães, 3\% de australianos e 5,6\% de americanos). Ainda, os brasileiros tendem a ver o assédio sexual (traduzido em inglês como sexual harassment) mais em termos de comportamento de sedução que pode ser inócuo, ao passo que americanos, australianos e alemães vêem-no como um abuso de poder, comportamento sexual prejudicial ou discriminação baseada em gênero.

Uma outra pesquisa mostrou importantes diferenças entre universitários brasileiros e americanos que leram uma versão hipotética de um artigo de jornal sobre um professor universitário que foi acusado por uma aluna de assédio sexual (DeSouza, Pryor \& Hutz, 1998). Os resultados indicaram que professor recebeu uma punição mais forte do que o estagiário; mulheres deram uma punição mais forte do que os homens e os norte americanos queriam mais punição para o assediador que os brasileiros, indicando mais tolerância sobre este tipo de comportamento no Brasil do que nos Estados Unidos. Quando apresentados com a possibilidade de que o caso fosse discriminatório, os brasileiros ficaram mais sensibilizados para o caso da aluna, vendo que talvez o comportamento sexual do assediador tenha efeitos realmente negativos nas mulheres. Porém isto não mudou as percepções dos norte americanos, talvez porque os mesmos percebam isto como problemático de qualquer Psicologia: Reflexão e Crítica, 2000, 13(3), pp.485-496 maneira. Interessante também foi o fato do interesse romântico ter diminuído a punição entres os sujeitos dos dois países, principalmente se este interesse tenha sido demonstrado por um professor em vez de um estagiário. Isto é problemático porque mesmo sem malícia, isto pode deixar alunas intimidadas e vulneráveis a abusos por parte de professores ou estagiários.

Várias perspectivas teóricas podem explicar diferenças de percepção entre os brasileiros, que vêem assédio sexual como uma forma de sedução (Pryor e cols., 1997) e os norte americanos que vêem assédio sexual como um problema social sério que merece uma punição forte (DeSouza e cols., 1998). Por exemplo, o modelo social/ cultural diz que a posição inferior da mulher na sociedade e no trabalho facilita o assédio sexual da mulher para manter a dominação do homem sobre ela (Tangri \& Hayes, 1997). Como há indicações que o brasileiros são mais machistas que os norte americanos (DeSouza e cols., 1998; Pryor e cols., 1997), não é surpreendente que os brasileiros vejam assédio sexual como uma coisa que não exista no Brasil, ou se existir, que os brasileiros não liguem tanto para isto como os norte americanos.

Uma teoria cultural diz que países/culturas são coletivistas (ou seja, que enfatizam conformidade as normas do grupo) ou individualistas (ou seja, nos quais os direitos e autonomia do indivíduo são enfatizados; Hofstede, 1980; Triandis, 1995). Vários fatores estão ligados ao coletivismo-individualismo como a percentagem de grupos étnicos num país. Norte americanos brancos (de descendência européia) são os mais individualistas nos Estados Unidos, com os negros, hispânicos, e asiáticos norte americanos sendo mais coletivistas (Triandis, 1995; Vandello \& Cohen, 1999). Como o Brasil tem uma percentagem bem menor de brancos que os Estados Unidos, não é surpreendente que o Brasil seja mais coletivista que os norte americanos. Ligado ao coletivismo, como em outras culturas latinas, as interações sociais de brasileiros são guiadas pelo conceito do personalismo (Garcia-Preto, 1982); ou seja, os brasileiros preferem evitar conflito ou confrontação.

$\mathrm{O}$ individualismo também está ligado à maior igualdade de gênero e aos direitos das mulheres. Isto é, o direito do indivíduo (incluindo a mulher e a pessoa de cor) é sagrado (em teoria) nos Estados Unidos, influenciando o direito das pessoas de não serem assediadas no trabalho. O Brasil é um país mais hierarquizado do que os Estados Unidos (da Matta, 1979). No Brasil, os homens se sentem socialmente e economicamente superiores as mulheres. O coletivismo e a hierarquização de gênero podem explicar por que só agora, na grande marcha pela reforma das questões das 
mulheres, é que o Brasil está prestando atenção ao assédio sexual.

Uma outra teoria que pode explicar as diferenças transculturais mencionadas acima é o clima da organização, como uma universidade, ou de uma parte da organização, como um departamento ou classe de aula (Fitzgerald e cols., 1997). Se o clima for tolerante a comportamento sexual, o assédio sexual aumenta. Há indicações que o Brasil é um país altamente sexualizado. Os brasileiros são extremamente gregários e constantemente invadem o espaço pessoal dos outros Eles gostam de aproximação física. Freqüentemente, tocam-se enquanto falam, ficam próximos a estranhos, abraçam-se e beijam-se quando cumprimentam colegas de trabalho e conhecidos, da mesma maneira que amigos. Tanto homens como mulheres brasileiras são mais livres ou abertos, sexualmente, nas suas conversas, como na mídia (Luft, 1995; Schreiberg, 1995), do que nos Estados Unidos. Se o clima no trabalho é sexualizado e é tolerado pelo chefe, ou se o próprio chefe de trabalho se comporta sexualmente com os seu empregados, as pessoas se sentem sem poder para fazer queixas ou para dete possíveis abusos, e os assediadores se sentem livres para assediar sem medo de punição.

É necessário que se explore mais a fundo as conotações e conseqüências do que é considerado assédio sexual entre as diversas culturas. Além disto, o assédio sexual é multifacetado, com interações complexas com fatores históricos, políticos, legais e sócio-psicológicos. Uma base teórica unidimensional é, no mínimo, limitada (ex. psicologia centrada na cultura americana).

\section{Conclusão}

No decorrer deste artigo, tem sido impossível separar gênero de raça e classe. Isto assemelha-se a experiência das mulheres nos Estados Unidos, como exemplificado pelo argumento de West e Fensternmaker (1997) que "nenhuma pessoa pode conhecer gênero sem simultaneamente conhecer raça e classe" (p. 60). O que pode se dizer sobre a luta pelos direitos das mulheres no Brasil é que ela fez grande progresso. Algumas evidências sugerem que o status das mulheres está aumentando em um ritmo quase que exponencial; estas mudanças são influenciadas e refletem as mudanças na sociedade como um todo. Por exemplo, o número de mulheres trabalhando fora de casa-um indicador da independência econômica e de status - cresceu de aproximadamente $20 \%$ em 1967, para atuais 70\% (Flight, 1995). No todo, a grande lacuna na distribuição de renda diminui levemente em 1995: os 10\% mais pobres da população ganharam $1 \%$ da renda nacional, se comparados com $0,7 \%$ em 1993 , enquanto os $10 \%$ mais ricos 47,1\%, comparado com 49\%, em 1993 (U.S. Department of State, 1997). Com a possível exceção de assédio sexual no ambiente de trabalho e escolar, as condições de trabalho estão melhorando (Sgarbieri, 1997). Contudo problemas sérios ainda permanecem, como evidencia a criação de um grupo interministerial pelo presidente Fernando Henrique Cardoso no final de 1995, para combater o que ele reconheceu publicamente como um sério problema brasileiro de racismo e discriminação de gênero (U.S. Department of State, 1997).

O que pode se dizer nesta análise é que o movimento das mulheres está fazendo progressos, embora algumas vezes comedidos, em várias esferas da sociedade. Cada questão mostra, ao mesmo tempo, progresso e estagnação, funcionamento sob tensão. Uma força parece mover adiante, mas é detida por outras forças que querem retê-la. Vê-se, nestas áreas de atividade social, um padrão. Os esforços de estagnação são atados a uma articulação ideológica de mulher como mãe, cuidadora, que merece ser protegida e guardada. Como se todos os retratos fossem do mesmo painel, em cada aspecto vemos a mesma imagem —o modelo de Maria. É como um filme holográfico, no qual cada parte contém em si a imagem do total (Hecht \& Baldwin, 1998). Ao mesmo tempo, só por ver todos retratos juntos podemos captar a complexidade e claridade completa do que é ser mulher (ou homem) no Brasil.

A perspectiva holográfica (Hecht \& Baldwin, 1998) sugere que uma intolerância particular, como o sexismo, terá um certo sabor da mesma intolerância em outros lugares e em tempos. Pois, provavelmente há similaridades entre o gênero no Brasil e em outras culturas. Ao mesmo tempo, por causa da articulação diferente, vai haver diferenças também. Pode-se ver que as questões no Brasil não são sempre as mesmas do que aquelas que preocupam as mulheres em outros países (ex.: creches não são uma grande questão para as mulheres americanas), e quando as questões são as mesmas, o conteúdo do debate pode variar significativamente com freqüência (ex.: planejamento familiar).

No Brasil, até nos movimentos para mudar os papéis e os direitos da mulher, vê-se a imagem de Maria nesta corrente de mudança. Pode ser este modelo que explica as particularidades do movimento para mulheres no Brasil. Não obstante a resistência que acompanha o modelo de Maria, este modelo também serve como veículo para o progresso e, além disso, provê às mulheres certas bases de poder, começando na esfera do lar. O que agora cabe às brasileiras - e aos brasileiros - é averiguar se a liberdade crescente para as mulheres se 
achará pelo modelo de Maria, num jeito completamente brasileiro, ou se, por fim, teremos que avançar além do modelo, descobrindo novos arquétipos para a mulher brasileira do futuro.

\section{Referências}

Alvarez, S. E. (1989). Politicizing gender and engendering democracy. Em S. Stepan (Org.), Democratizing Brazil: Problems of transition and consolidation (pp. 205-251). New York: Oxford University Press

Alvarez, S. E. (1990). Engendering democracy in Brazil: Women's movements in transition politics. Princeton: Princeton University Press.

Americas Watch. (1991). Criminal injustice: Violence against women in Brazil. Human Rights Watch: New York.

Arrazola, L. D. \& Rocha, I. (1996). Mulher, natureza, cultura: Apontamentos para um debate. Em G. Rabay (Org.), Mulberes e sociedade (pp. 45-55). João Pessoa: UFPB/Editora Universitária.

Araújo, E. (1993). O teatro dos vícios: Transsressãa e transigenncia na sociedade urbana colonial. Rio de Janeiro: José Olympio.

Baca Zinn, M. (1982). Chicano men and masculinity. Journal of Ethnic Studies, 10, 20-44.

Barker, G. \& Loewenstein, I. (1997). Where the boys are: Attitudes related to masculinity, fatherhood, and violence toward women among lowto masculinity, fatherhood, and violence toward women among low-
income adolescents and young adult males in Rio de Janeiro, Brazil. income adolescents and you
Youth \& Society, 29, 166-196.

Youth \& Society, 29, 166-196.
Berquo, E. (1989). The demographic effects of contraception - the decline in fertility.

Berquo, E. (1989). The demographic effects of contraception-the decline in fertility
When the patient is a woman. Brasilia, DF: National Council of Women's When the patient is a woman. B
Rights-Ministry of Justice.

Boff, L. (1992). Churcb: Charism \& power. Liberation Theology and the institutional cburch. NewYork: Crossroad.

Brooke, J. (1982, 02 de Janeiro). Feminism in foreign lands: Two perspectives: Macho killing in Brazil spurs protests. Boston Globe, A23-24.

Burns, E. B. (1993). A bistory of Brazil ( $3^{a}$ ed.). New York: Columbia Universi-

ty Press.
Casas, J. M., Wagenheim, R. B. \& Mendoza-Romero, J. (1995). Hispanic masculinity: Myth or psychological schema meriting clinical
mastic consideration. Em A. M. Padilla (Org.), Hispanic psychology: Critical issues in theory and research (pp. 231-244). Thousand Oaks: Sage.

Conniff, M. L. \& McCann, F. D. (1989). Epilogue. Em M. L. Conniff \& F. D. McCann (Orgs.), Modern Brazil: Elites and masses in historical perspective (pp. 265-280). Lincoln: University of Nebraska.

da Costa, E. V. (1985). The Brazilian empire: Myths and histories. Chicago: University of Chicago Press.

da Matta, R. (1979). Carnavais, malandros e heróis: Para uma sociologia do dilema brasileiro. Rio de Janeiro: Zahar.

Del Priore, M. (1993). Ao sul do corpo: Condicão feminina, maternidades e mento lidades no Brasil Colonia. Rio de Janeiro: José Olympio.

DeSouza, E. R. (1998). Comportamento humano numa vila global: Uma perspectiva pós-moderna (construtivista) sobre psicologia comunitária do Terceiro Mundo. Psicologia: Reflexão e Crítica, 11, 147-160.

DeSouza, E. R. \& Hutz, C. S. (1995). Responses toward sexual stimuli in Brazil as a function of one's gender role identity and sex. Interameric Journal of Psychology, 29, 13-21.

DeSouza, E. R. \& Hutz, C. S. (1996). Reactions to refusals of sexual advances among U. S. and Brazilian men and women. Sex Roles, 34, 549-565.

DeSouza, E., Madrigal, C. \& Millan, A. (1999). A cross-cultural validation of the Multidimensional Condom Attitudes Scale. Interamerican Journal of Psychology, 33, 191-204.

DeSouza, E. R., Pierce, T., Zanelli, J. C. \& Hutz, C. (1992). Perceived sexual intent in the U. S. and Brazil as a function of nature of encounter, subjects' nationality, and gender. Journal of Sex Research, 29, 251-260.

DeSouza, E. R., Pryor, J. B. \& Hutz C. S. (1998). Reactions to sexual harassment charges between North Americans and Brazilians. Sex Roles, 39, 913-928.

Psicologia: Reflexão e Crítica, 2000, 13(3), pp.485-496
Equal Employment Opportunity Commission. (1980). Guidelines and discrimination because of sex. (Sex. 1604.11). Federal Register, 45, 74676 74677

Fitzgerald, L. F., Drasgow, F. Hulin, C. L., Gelfand, M. J. \& Magley, V. (1997). Antecedents and consequences of sexual harassment in organizations: A test of an integrated model. Journal of Applied Psychology, 82, 578-589.

Fitzgerald, L. F. \& Hesson-McInnis, M. (1989). The dimensions of sexual harassment: A structural analysis. Journal of Vocational Behavior, 35, 309326.

Flight (1995). Flight to the cities: Brazil's women fight against age-old machismo and new urban violence. (Sept. 1995). Mother Jones, 46.

Foucault, M. (1978). The bistory of sexuality. New York: Princeton University Press.

Freitas, M. G. M. (1996). Identidade feminina/feminista da mulher negra: Uma construção marcada pela negação, subalternidade e resistência Em G. Rabay (Org.), Mulheres e sociedade (pp. 45-55). João Pessoa: UFPB/ Editora Universitária.

Garcia-Preto, N. (1982). Puerto Rican families. Em M. McGoldrick, J. K Pearce \& J. Giordano (Orgs.), Etbmicity and family therapy (pp. 164-186). New York: Guilford Press.

Gelfand, M. J., Fitzgerald, L. F. \& Drasgow, F. (1995). The structure of sexual harassment: A confirmatory factor analysis across cultures and settings. Journal of Vocational Behavior, 47, 164-177.

González, A. (1982). Sex-roles of the traditional Mexican family: A comparison of Chicano and Anglo students' attitudes. Journal of CrossCultural Psychology, 13, 330-339.

Graham, R. (1990). Patronage and politics in nineteenth-century Brazil. Stanford: Stanford University Press.

Hahner, J. E. (1990). Emancipating the female sex: The struggle for women's rights in Brazil, 1850-1940. Durham: Duke University Press.

Hall, M. H. \& Garcia, M. A. (1989). Urban labor. Em M. L. Conniff \& F. D. McCann (Orgs.), Modern Brazil: Elites and masses in historical perspective (pp. 161-191). Lincoln: University of Nebraska.

Hall, S. (1992). New ethnicities. Em J. Donald \& A. Rattansi (Orgs.), Race, culture \& difference (pp. 252-259). London: Sage.

Hecht, M. L. \& Baldwin, J. R. (1998). Layers and holograms: A new look at prejudice. Em M. L. Hecht (Org.), Communication of prejudice (pp. 57-
(n) 84). Thousand Oaks: Sage.

Hofstede, G. (1980). Culture's consequences. Beverly Hills, CA: Sage.

IBGE. (1984). Censos demográficios e PNAD-1984, Suplemento especial de fecundidade Brasilia: IBGE

Lara-Cantú, M. A. \& Navarro-Arias, R. (1987). Self-descriptions of Mexican college students in response to the Bem Sex Role Inventory and other sex role items. Journal of Cross-Cultural Psychology, 18, 331-344.

Larch, P. B. (1982). An explanation of the predominance of women in the Umbanda cults of Porto Alegre, Brazil. Urban Anthropology, 11, 237261

Levine, R. M. (1989). Elite perceptions of the povo. Em M. L. Coniff \& F. D. McCann (Orgs.), Modern Brazil: Elites and masses in historical perspective (pp. 209-224). Lincoln: University of Nebraska.

Luft, K. (1995, 18 de Julho). Brazilian TV reveals a bit too much, risks regulation. Chicago Tribune, 1, 8.

McCann, F. D. \& Conniff, M. L. (1989). Introduction. Em M. L. Coniff \& F. D. McCann (Orgs.), Modern Brazil: Elites and masses in historical perspective (pp. ix-xxvi). Lincoln: University of Nebraska Press

Mendes-Leite, R. (1993). A game of appearances: The "ambigusexuality" in Brazilian culture of sexuality. Journal of Homosexuality, 25, 271-282. Miele, N. (1992). Syndicat: Une affaire de femme. Etude sur les femmes présidentes des Syndicats des Travailleurs ruraux de l'Etat de Paraiba au Brésil. Université de Picardie, Picardie, França

Miele, N. (1994, Novembro). Paraiba feminina, mulber forte, sim senhor! Pesquisa apresentada na XVIII Conferência Anual de ANPOCS. Caxambú, Minas Gerais: ANPOCS. 
Miller, C. (1979). The function of middle-class extended family networks in Brazilian urban society. Em M. Margolis \& W. Carter (Orgs.), Braz Antropological perspectives (pp. 305-316). New York: Columbia Universit Press.

Mirandé, A. (1985). The Chicano experience: An alternative perspective. Notre Dame, IN: University of Notre Dame Press.

Muraro R. M. (1983). Sexualidade da mulher brasileira: Corpo e classe social no Brasil ( $2^{a}$ ed.). Petrópolis, RJ: Vozes.

Muraro, R. M. (1992). A mulher no terceiro mundo. Rio de Janeiro: Paz e Terra. Nelson, S. (1996). Constructing and negotiating gender in women's police stations in Brazil. Latin American Perspectives, 88, 131-148.

Neto, M. M. (1996). Relações de poder e violência contra a mulher. Em G. Rabay (Org.), Mulberes e sociedade (pp. 45-55). João Pessoa: UFPB/Editora Rabay (Org.), Mulheres e sociedade (pp. 45-55). João Pessoa: UFPB/Editor Universitária.

Neuhouser, K. (1989). Sources of women's power and status among the urban poor in contemporary Brazil. Signs, 14, 685-702.

Parker, R. G. (1988). "Within four walls": The cultural construction of sexual meanings in contemporary Brazil. Tese de Doutorado não publicada, University of California, Berkeley, Califórnia, EUA.

Parker, R. G. (1993). "Within four walls": Brazilian sexual culture and HIV/AIDS. Em H. Daniel \& R. Parker (Orgs.), Sexuality, politics and AIDS in Brazil: In another world? (pp. 65-84). London: Falmer.

Patai, D. (1991). Introduction [to Women and the New Brazilian Constitution]. Feminist Studies, 17, 551-556.

Pescatello, A. (1973). The brasileira: Images and realities in writings of Machado de Assis and Jorge Amado. Em A. Pescatello (Org.), Female and male in Latin America: Essays (pp. 29-58). Pittsburgh: University of and male in Latin America: Essays (pp. 29-58). Pittsburgh: University of Pittsburgh Press.

Pryor, J. B., DeSouza, E. R., Fitness, J., Hutz, C., Kumpf, M., Lubbert, K, Pesonen, O. \& Erber, M. W. (1997). Gender differences in the interpretation of social-sexual behavior: A cross-cultural perspective on sexual harassment. Journal of Cross-Cultural Psychology, 28, 509-534.

Rabay, G. (1996). Mulher e participação política na Paraiba. Em G. Rabay (Org.), Mulheres e sociedade (pp. 203-212). João Pessoa: UFPB/Editor Universitária.

Reid, P. T. (1993). Poor women in psychological research: Shut up and shout out. Psychology of Women Quarterly, 17, 133-150.

Santana, J. S. S. (1996). A creche como elemento contributivo para inserção da mulher no mercado de trabalho. Em G. Rabay (Org.), Mulberes e da mulher no mercado de trabalho. Em G. Rabay (Org.), Mull
sociedade (pp. 45-55). João Pessoa: UFPB/Editora Universitária.
Schreiberg, D. (1995, 09 de Outubro). Samba warnings: Porn and promiscuity provoke backlash. Newsweek, 52 .

Sgarbieri, A. N. (1997, Maio). "Women -The great change in Brazill': Changes in discourse about women in the workplace and in the press. Pesquisa apresentada na Conferência Internacional IV na Linguagem e Psicologia Social, Ottawa, Canadá

Sorenson, S. B. \& Siegel, J. M. (1992). Gender, ethnicity, and sexual assault: Findings from a Los Angeles study. Journal of Social Issues, 48, 93-104. Stevens, E. (1973). Machismo and marianismo. Society, 10, 57-63.

Tangri, SS. \& Hanes, S. ML (1997). Theories of sexul hat 57-63. Em. W. O'Donohue (Org.), Sexual harassment: Theory, research, and treatment (pp. 112-128). Needham Heights, MA: Allyn \& Bacon. Thom D. Q. \& Be Hey, D. E. (1993). Donesic vilnc

Thas, D. Q. \& Beasley, M. E. (1993). Domestic violence as a human rights issue. Human Rights Quarterly, 15, 36-62.

Topik, S. (1989). The Old Republic. Em M. L. Coniff \& F. D. McCann (Orgs.), Modern Braril: Elites and masses in historical perspective (pp. 83-102). Lincoln: University of Nebraska

Triandis, H. C. (1995). Individualism and collectivism. Boulder, CO: Westview Press.

UNICEF. (1990). Situagãa mundial da infância. Brasilia: UNICEF.

U.S. Department of State. (1997). Brazil Country Report on Human Rights Practices for 1996. Washington, DC: Bureau of Democracy, Human Rights, and Labor.

Vandello, J. A. \& Cohen, D. (1999). Patterns of individualism and collectivism across the United States. Journal of Personality and Social Psychology, 77 , 279-292

van den Berghe, P. L. (1967). Race and racism: A comparative perspective. New York: John Wiley

Verucci, F. (1991). Women and the new Brazilian Constitution. Feminist Studies, 17, 557-568.

West, C. \& Fensternmaker, S. (1997). Doing difference. Em M. R. Walsh (Org.), Women, men and gender: Ongoing debates (pp. 58-72). New Haven: Yale University Press.

World's women. (1995). World's women. New York: United Nations.

Recebido em 05.10.1999 Primeira revisão em 20.11 .1999 Segunda revisão em 10.03 .2000 Aceito em 08.06.2000

Sobre os autores:

Eros DeSouza é Psicólogo, Doutor pela University of Kansas (EUA) e Professor da Illinois State University (EUA).

John R. Baldwin é Psicólogo e Professor da Illinois State University (EUA).

Francisco Heitor da Rosa é Psicólogo e Mestre em Psicologia do Desenvolvimento pela Universidade Federal do Rio Grande do Sul. 